\title{
Application of Nonlinear Adaptive Control in Temperature of Chinese Solar Greenhouses
}

\author{
Yonggang Wang, Yujin Lu * and Ruimin Xiao
}

check for updates

Citation: Wang, Y.; Lu, Y.; Xiao, R. Application of Nonlinear Adaptive Control in Temperature of Chinese Solar Greenhouses. Electronics 2021 10, 1582. https://doi.org/10.3390/ electronics10131582

Academic Editor: Manohar Das

Received: 19 May 2021

Accepted: 28 June 2021

Published: 30 June 2021

Publisher's Note: MDPI stays neutral with regard to jurisdictional claims in published maps and institutional affiliations.

Copyright: (c) 2021 by the authors. Licensee MDPI, Basel, Switzerland. This article is an open access article distributed under the terms and conditions of the Creative Commons Attribution (CC BY) license (https:// creativecommons.org/licenses/by/ $4.0 /)$.
College of Information and Electronic Engineering, Shenyang Agricultural University, Shenyang 110866, China; wygvern@syau.edu.cn (Y.W.); xrm@stu.syau.edu.cn (R.X.)

* Correspondence: lyj@stu.syau.edu.cn; Tel.: +86-151-4215-8410

\begin{abstract}
The system of a greenhouse is required to ensure a suitable environment for crops growth. In China, the Chinese solar greenhouse plays a crucial role in maintaining a proper microclimate environment. However, the greenhouse system is described with complex dynamic characteristics, such as multi-disturbance, parameter uncertainty, and strong nonlinearity. It is difficult for the conventional control method to deal with the above problems. To address these problems, a dynamic model of Chinese solar greenhouses was developed based on energy conservation laws, and a nonlinear adaptive control strategy combined with a Radial Basis Function neural network was presented to deal with temperature control. In this approach, nonlinear adaptive controller parameters were determined through the generalized minimum variance laws, while unmodeled dynamics were estimated by a Radial Basis Function neural network. The control strategy consisted of a linear adaptive controller, a neural network nonlinear adaptive controller, and a switching mechanism. The research results show that the mean errors were 0.8460 and 0.2967 , corresponding to a conventional PID method and the presented nonlinear adaptive scheme, respectively. The standard errors of the conventional PID method and the nonlinear adaptive control strategy were 1.8480 and 1.3342 , respectively. The experimental results fully prove that the presented control scheme achieves better control performance, which meets the actual requirements.
\end{abstract}

Keywords: Chinese solar greenhouse; temperature control; nonlinear adaptive control; radial basis function neural network

\section{Introduction}

A greenhouse is devised to create a more favorable climate, such as enough solar radiation, adequate temperatures, and suitable humidity, to protect plants and promote the growth of crops [1-3]. Chinese solar greenhouses (CSGs) produce a significant annual output, which has large economic and social benefits in China. Therefore, considerable attention has been given to the CSG in order to provide a proper environment for crop growth. However, in Northeast China, the average temperatures are very low, even falling to below $-10{ }^{\circ} \mathrm{C}$, and the cold season generally lasts for four months due to the high latitude in some areas [4]. Such arctic weather seriously affects normal production and brings great loss to the economic benefits [5]. Therefore, the structure of the CSG is different from other countries due to the variability of weather in Northeast China, which usually consists of a south roof, a north roof, a north wall and a thermal blanket for supplying pollution-free and high-quality vegetables even during the winter.

A great many modeling methods for greenhouses have already been proposed such as mechanism, transfer function and black-box modeling [6]. The Takagi-Sugeno fuzzy model was developed according to the historical data of greenhouses [7]. A modeling approach was built using the data collected from an actual greenhouse under closedloop control [8]. Online identification technology was adopted to obtain a more accurate greenhouse model [9]. A stochastic dynamic model based on parameter identification was proposed through the maximum likelihood estimation method [10]. It should be noted that 
dynamic models of greenhouses in different areas have differences owing to construction and covering materials, which directly affect the internal environmental conditions, such as temperature and relative humidity. Therefore, the dynamic model of the CSG is different from other greenhouse because of its special structure.

The inside temperature is a significant factor in restricting greenhouse production in Northeast China [11]. In this situation, the CSG must maintain a certain indoor temperature level to meet the needs of crop growth. Furthermore, determining automatic control strategies is the leading goal for obtaining higher-quantity greenhouse crops. A classical feedback controller, such as the PID control method [12], has been widely used in various fields. However, the control of inside temperatures has generally confronted a series of difficulties in applying the classical feedback control strategy due to its inherent stochastic complexity properties as follows:

(1) The greenhouse is considered a nonlinear dynamic system with intensive multidisturbance from surroundings, such as global radiation, humidity, and outside air temperature $[13,14]$;

(2) The control process is severely influenced by instable factors including global radiation, external weather, and human activities;

(3) The crops and the environment have a strong and interactive relationship [15]. For example, the plants transpiration and photosynthesis similarly affect the greenhouse temperature that they depend on.

During recent years, many scholars have proposed advanced control strategies, such as adaptive control [16,17], feedforward control [18,19], optimal control [20,21], fuzzy control [22,23], robust control [24,25], and so on. These control methods can ensure the inside temperature near the temperature set point in certain conditions. However,, the problems caused by the instable factors and multi-disturbances are still difficult to deal with. Furthermore, most of these climate control strategies are difficult to carry out in greenhouse production due to the theoretical complex.

Deterministic artificial intelligence can deal with deterministic self-awareness statements based on either the physics of the underlying problem or system identification to establish governing deferential equations [26]. Furthermore, stochastic artificial intelligence, such as neural network technologies, can be expressed in stochastic algorithms in the face of stochastic disturbances. Adaptive controller design of a nonlinear system with discrete-time characteristics was studied using neural networks [27]. The stochastic neural adaptive tracking control problem of an indeterminate switched nonlinear system with a non-strict feedback characteristic was investigated in [28]. The adaptive neural network control scheme was presented to solve the accurate and robust control problem of nonlinear systems with unknown dynamics [29]. The adaptive neural network controller, based on the technique of backstepping, was proposed for the consensus tracking control problem [30]. A nonlinear adaptive decoupling switching control strategy using neural networks was studied to improve the closed-loop performance and evaporation efficiency [31].

The above considerations motivated our study. In particular, inspired by the modeling method and control method in [32-34], this paper starts with the development of a dynamic model of the CSG and proposes a nonlinear adaptive control scheme based on Radial Basis Function (RBF) neural networks to solve temperature control for the CSG system. The main contributions of this paper are summarized as follows:

(1) In order to make the dynamic model more accurate and closer to the actual system, heat transfer quantities of the north wall and north roof were respectively added to the dynamic model in this paper. In addition, the cold air penetration was added to the humidity balance model;

(2) To the best of our knowledge, almost no research so far has addressed the fact that the existing control scheme based on RBF has been applied to the CSG considering the nonlinearity and adaptiveness. This control approach takes advantage of the strong ability of learning and adaptability of RBF neural networks. In this paper, a linear 
adaptive controller, a neural network nonlinear adaptive controller, and switching mechanism were combined to improve dynamic performance on the promise of guaranteeing system stability. The parameters of the controller were determined based on the generalized minimum variance control law. An RBF neural network was employed to solve the unmodeled dynamics of CSGs. The experimental results express that the presented control strategy shows quick set-point tracking ability in the case of multi-disturbances and can achieve satisfactory control performances.

\section{Materials and Methods}

\subsection{CSG Facility}

The research on modeling and control was performed in an experimental greenhouse located at Shenyang Agricultural University in Liaoning Province $\left(41.48^{\circ} \mathrm{N}, 123.24^{\circ} \mathrm{E}\right.$, and $42 \mathrm{~m}$ a.s.l. (above sea level)). The CSG architecture schematic is shown in Figure 1. The greenhouse was $60 \mathrm{~m}$ long and $12 \mathrm{~m}$ wide. The heights of the north wall and north roof were $3 \mathrm{~m}$ and $5.5 \mathrm{~m}$, respectively. The north wall was a $0.6 \mathrm{~m}$ thick layered structure consisting of brick, insulation polystyrene foam, and air layer. The cover of the south roof was made of a $0.00012 \mathrm{~m}$ thick polyvinyl chloride film, and a $0.02 \mathrm{~m}$ thick cotton blanket was used for thermal insulation at night.

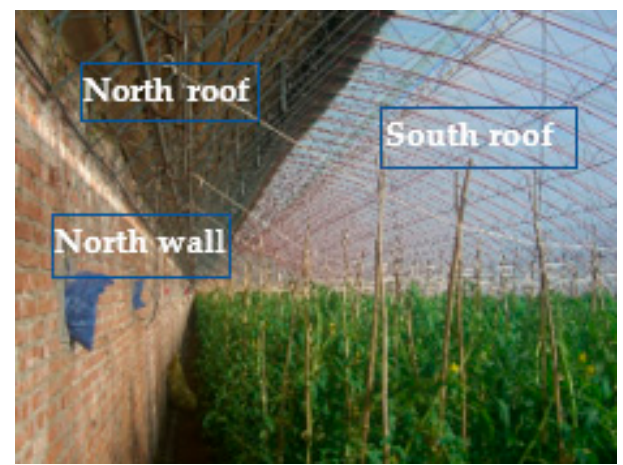

(a)

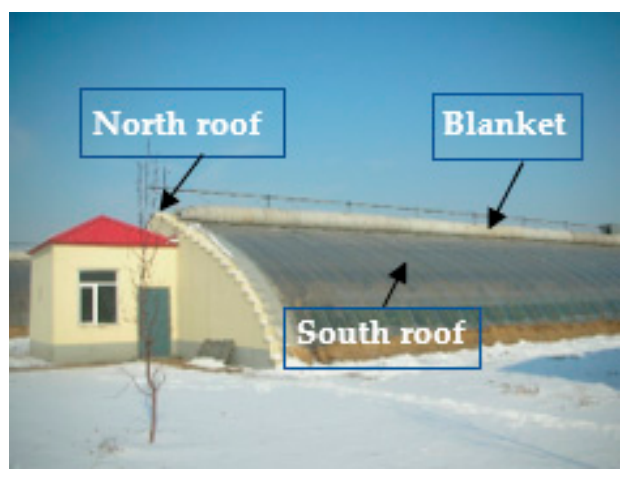

(b)

Figure 1. Architecture schematic of the (a) inside, and (b) outside of a CSG.

For measurement of the ambient parameters, different sensors were installed in the experimental greenhouse. The type of temperature and humidity sensor used was the SHT10 (Sensirion, Zurich, Switzerland), which can measure the temperature and humidity simultaneously. Eighteen sensors were installed in the experimental greenhouse. A distribution diagram of environmental sensors is shown in Figure 2. The locations of sensors were installed every $18 \mathrm{~m}$ and two sets of sensors were installed at each location. The sensors were placed horizontally at different heights above the ground $(1.5,3$, and $4.5 \mathrm{~m})$. The mean of the temperature and humidity recorded by the eighteen installed sensors was considered as the temperature inside the greenhouse. The inside solar radiation and outside solar radiation were measured by a pyranometer (MP200, Apogee Instruments, Logan, UT, USA). The outside temperature, outside humidity, and the direction and velocity of the wind were collected from an outer weather station. The sample interval of parameters was $5 \mathrm{~s}$ and the mean of every $900 \mathrm{~s}$ was recorded for all variables. 


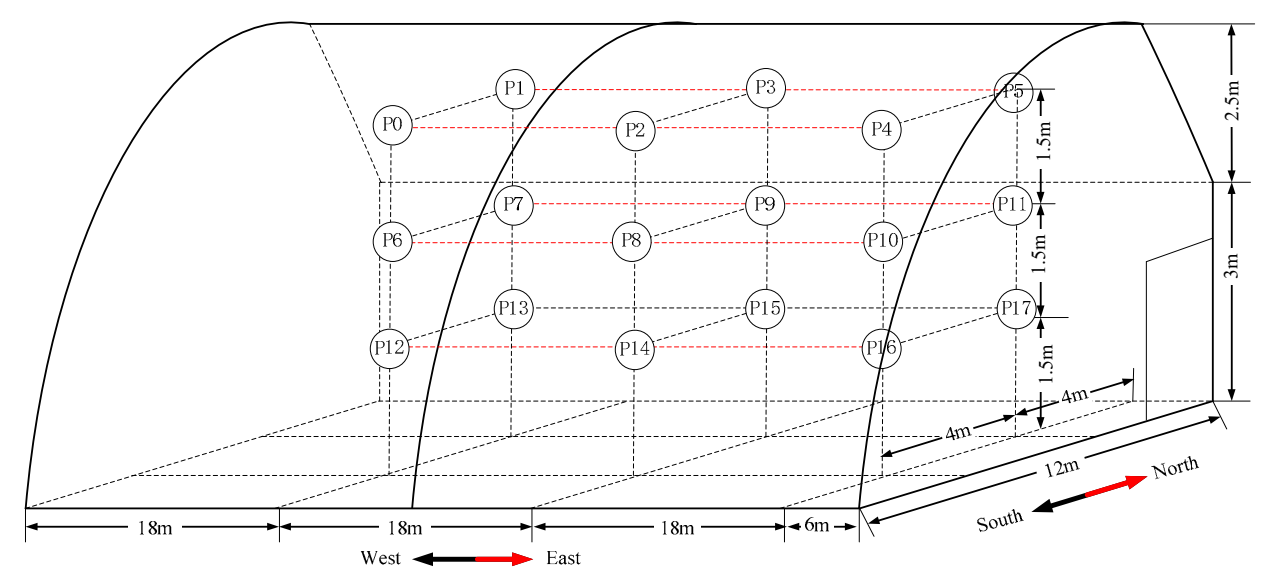

Figure 2. Distribution diagram of environmental sensors.

The Shenyang district (in Northeast China) is classified as a monsoon climate, and has a wide temperature range. Influenced by the monsoon, winters are long, lasting nearly five months. Solar radiation is able to provide part of the heat for plant growth. However, during the night or bad weather such as snow with insufficient light intensity, the greenhouse plays a crucial role in maintaining an appropriate temperature in order to prevent the plants from damage, which would markedly decrease their production rate. Therefore, it is common to regulate the temperature in these areas during the winter, especially for value-added crops, such as strawberry or mushroom.

\subsection{Greenhouse Model Description}

The greenhouse dynamic model is usually obtained according to the energy conservation principle [35]. Considering the characteristics of the unique structure in CSGs, heat transfer quantity $Q_{w}\left(\mathrm{~W} / \mathrm{m}^{2}\right)$ and $Q_{m}\left(\mathrm{~W} / \mathrm{m}^{2}\right)$ are introduced from inside air to the north wall and north roof, respectively [36]. The greenhouse model was developed in this paper according to energy balance (Figure 3). These differential equations are given by:

$$
\left\{\begin{array}{l}
\frac{d T_{\text {in }}}{d t}=\frac{Q_{\text {rad }}+Q_{h e a t}-Q_{c}-Q_{n}-Q_{s}-Q_{m}-Q_{w}-Q_{r}}{\rho C_{P} h} \\
\frac{d H_{i n}}{d t}=\frac{E-C-\phi_{a}-\phi_{e}}{h}
\end{array}\right.
$$

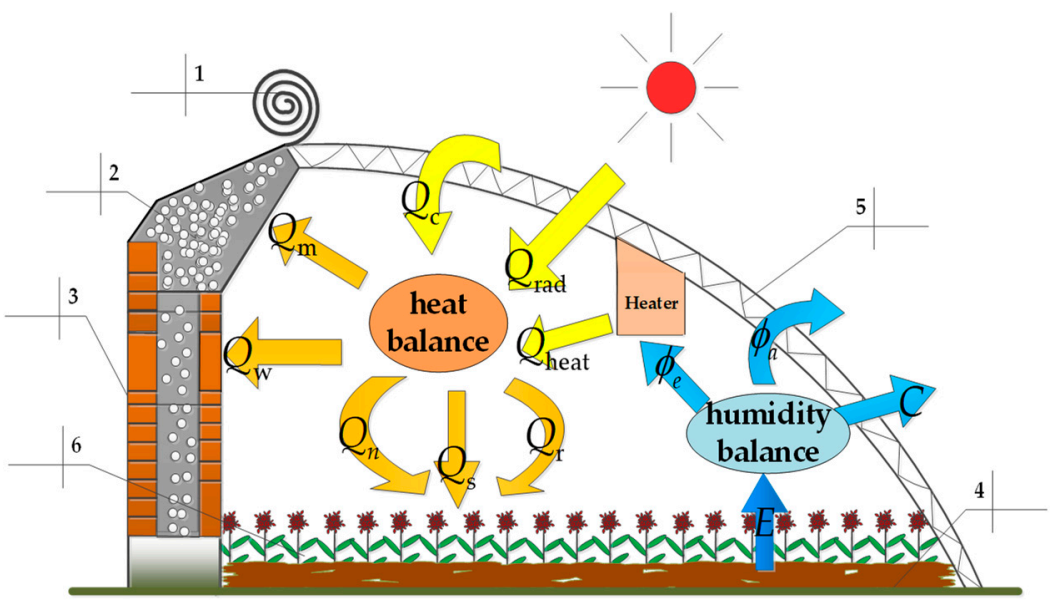

Figure 3. Schematic diagram of energy balance of experimental greenhouse. (Note: 1 . the greenhouse blanket; 2 . the north roof; 3 . the north wall; 4 . the soil; 5 . the greenhouse frame; 6 . crops).

In the heat model of Equation (1), where $\rho$ is the air density, $C_{P}$ is air specific heat capacity, $h$ is the height of the greenhouse, $Q_{\text {rad }}\left(\mathrm{W} / \mathrm{m}^{2}\right)$ is the intercepted solar radiant 
energy, $Q_{\text {heat }}\left(\mathrm{W} / \mathrm{m}^{2}\right)$ is the heat provided by the greenhouse heaters, $Q_{c}\left(\mathrm{~W} / \mathrm{m}^{2}\right)$ is the heat transferred from the envelope between the outside and the inside, $Q_{r}\left(\mathrm{~W} / \mathrm{m}^{2}\right)$ is the heat absorbed by the crops through transpiration, $Q_{n}\left(\mathrm{~W} / \mathrm{m}^{2}\right)$ is the sensible heat transferred from inside air to crops, $Q_{s}\left(\mathrm{~W} / \mathrm{m}^{2}\right)$ is the heat transferred from inside air to the soil in the greenhouse, $Q_{w}\left(\mathrm{~W} / \mathrm{m}^{2}\right)$ is the sensible heat transferred from the north wall to indoor air, and $Q_{m}\left(\mathrm{~W} / \mathrm{m}^{2}\right)$ is the sensible heat transferred from north roof to inside air.

In the humidity model of Equation (1), where $E$ is the transpiration rate of crops in $\mathrm{g} \cdot \mathrm{m}^{-2} \cdot \mathrm{s}^{-1}, \mathrm{C}$ is the water vapor condensation caused by the indoor and outdoor temperature difference in $\mathrm{g} \cdot \mathrm{m}^{-2} \cdot \mathrm{s}^{-1}, \phi_{a}$ is the humidity taken away by the cold air penetrating the greenhouses in $\mathrm{g} \cdot \mathrm{m}^{-2} \cdot \mathrm{s}^{-1}$ and $\phi_{e}$ is the water condensation or evaporation when heating system is activated in $\mathrm{g} \cdot \mathrm{m}^{-2} \cdot \mathrm{s}^{-1}$.

According to the well-known Penman-Monteith formula, $Q_{r}$ can be circulated by [37]:

$$
Q_{r}=C_{l} R_{n}+\left(\frac{e_{s} \beta}{\gamma}\right) T_{i n}-\left(\frac{h_{l} P}{8.036 \gamma}\right) H_{i n}
$$

where $C_{l}$ is the convective heat loss coefficient from indoor air to the cover, $R_{n}$ is the net radiative exchange between the canopy and the environment, $e_{s}$ is the air saturation vapor pressure, $\beta$ is the influence coefficient of temperature change on saturated water vapor pressure, $\gamma$ is the psychrometric constant, $h_{l}$ is the heat transfer constant between crops and inside air, and $P$ is the standard atmospheric pressure. $H_{i n}$ indicates the absolute humidity of the indoor air.

Solar radiation, a significant factor affecting the indoor temperature, is defined as [38]:

$$
Q_{\text {rad }}=\frac{c_{1} \tau S_{\text {out }} A_{\text {gr }} \sin I^{o}}{V_{a}}
$$

where $c_{1}$ is the aging coefficient of lighting material, $\tau$ is the greenhouse global transmission, $S_{\text {out }}$ is the solar radiation, $A_{g r}$ is surface area of greenhouse which absorbs solar radiation, $\sin I^{o}$ is the incidence angle of sunlight, and $V_{a}$ is the volume of the greenhouse.

In this study, the air heating adopted by heating equipment, the energy provided by which is calculated as [39]:

$$
Q_{\text {heat }}=\frac{\eta Q_{P}}{A_{g r}}
$$

where $\eta$ is the energy efficiency of heaters and $Q_{P}$ is the energy power of the heating equipment in $\mathrm{W} / \mathrm{m}^{2}$.

$Q_{c}$ can be expressed as follows [40]:

$$
Q_{c}=h_{C}\left(t_{\text {in }}-t_{\text {out }}\right)\left(\frac{A_{s u}}{A_{g r}}\right)
$$

where $t_{\text {in }}$ and $t_{\text {out }}$ are the inside and outside temperatures in ${ }^{\circ} \mathrm{C}$, respectively. $A_{s u}$ is the superficial area of cover materials. The conversion relation between $t$ and $T$ is as follows:

$$
t=T-273.15
$$

The overall energy loss coefficient $h_{c}$, increasing with wind speed $v_{\text {out }}$, is defined as the formula [38]:

$$
h_{c}=A+B v_{\text {out }}
$$

Single-layer and double-layer covering materials are different. Generally, CSGs use a single-layer covering material. In this paper, the values of $A$ and $B$ were 6 and 0.5 , respectively.

In this paper, the heat transfer into the greenhouse environment was also considered. In Equation (1), $Q_{n}$ and $Q_{s}$ are calculated as follows [13]:

$$
Q_{n}=\left(T_{i n}-T_{l}\right) \rho C_{P} / r_{a}
$$




$$
Q_{s}=\left(T_{i n}-T_{s}\right) \rho C_{P} / r_{a}
$$

where: $T_{S}$ is soil surface temperature and $T_{l}$ represents the leaf temperature of crops.

Under existing conditions in the CSG, this paper calculated the aerodynamic resistance of soil by means of following formula [37]:

$$
r_{a}=305\left(D / v_{\text {in }}\right)^{0.5}
$$

where: $D$ is the leaf width and $v_{\text {in }}$ is indoor wind speed.

Heat transfer quantity $Q_{w}$ is calculated as follows:

$$
Q_{w}=A_{w} \alpha_{w}\left(T_{i n}-T_{w}\right)
$$

where: $A_{w}$ is the north wall area, $T_{w}$ represents the north wall temperature and $\alpha_{w}$ is the convective heat transfer coefficient between the north wall and the inside air.

Heat transfer quantity $Q_{m}$ is calculated as follows:

$$
Q_{m}=A_{h} \alpha_{h}\left(T_{i n}-T_{h}\right)
$$

in which $A_{h}$ is the area of the north roof, $T_{h}$ represents the north roof temperature and $\alpha_{h}$ is the convective heat transfer coefficient between the north roof and the inside air.

$$
E=\frac{C_{l} R_{n}+\left(e_{s} \beta / \gamma\right) T_{\text {in }}-\left(h_{l} P / 8.036 \gamma\right) H_{\text {in }}}{\lambda}
$$

where $\lambda$ is latent heat of evaporation.

$$
C=0.00164\left(A_{r} / A_{g r}\right)\left(T_{i n}^{\prime}-T_{r}^{\prime}\right)^{1 / 3}\left(H_{i n}-H_{s, r}\right)
$$

in which, $A_{r}$ is the greenhouse covering the area in $\mathrm{m}^{2}$ and $T_{i n}^{\prime}$ is the virtual temperature of indoor air. Equation (15) is the formula of $T_{i n}^{\prime}$ and $T_{r}^{\prime}$, where $e_{a}$ represents the actual water vapor pressure of indoor air.

$$
T^{\prime}=T\left(1+0.378 e_{a} / P\right)
$$

where the absolute humidity of air saturated water under the plastic covering film $H_{s, r}$ is defined by:

$$
H_{s, r}=2165 e_{a} / P
$$

In Equation (1), $\phi_{e}$ and $\phi_{a}$ are calculated as follows [41]:

$$
\begin{gathered}
\phi_{e}=\left(\frac{\eta A_{r} h_{P}}{A_{g r} \lambda}\right) Q_{P} \\
\phi_{a}=\psi_{a}\left(H_{\text {in }}-H_{\text {out }}\right)
\end{gathered}
$$

Due to geographical factors, winter in Northeast China is cold and dry with strong winds. This cold wind is an important factor affecting greenhouse humidity. Therefore, cold air penetration was added to the humidity balance model. The calculation equation is shown in Equation (19):

$$
\psi_{a}=\frac{\varepsilon V_{a}}{3600}
$$

Cold air infiltration, $\psi_{a}$, is greatly influenced by outdoor wind speed, and $\varepsilon$ represents the cold air infiltration coefficient, the value of which is different with the outdoor wind speed and generally lies between 0.2 and 0.5 .

Equations (2)-(12) were substituted into Equation (1) to obtain the temperature dynamic model of the system, which is shown in Equation (20). Equations (13)-(19) were 
substituted into Equation (1) to acquire the humidity dynamic model of the system, which is shown in Equation (21). The model parameters are provided in Appendix A in Table A1.

The dynamic model of CSG shows that the model parameters, such as global radiation, outside wind speed, and outside air temperature, reflect stochastic properties. Therefore, the CSG system is a complex system characterized by uncertain parameters. Moreover, the process of CSG is a nonlinear system because dynamic models contain nonlinear items.

$$
\begin{aligned}
& \dot{T_{i n}}(t)=\left[-\frac{h_{c} A_{s u}}{A_{g r} \rho C_{P} h}-\frac{2}{305\left(\frac{D}{v_{i n}}\right)^{0.5} h}-\frac{A_{h} \alpha_{h}}{\rho C_{P} h}-\frac{A_{\text {w }} \alpha_{i v}}{\rho C_{P} h}-\frac{e_{s} \beta}{\rho C_{P} h r}\right] T_{i n}(t)+\frac{h_{l} P}{8.036 \gamma \rho C_{P} h} H_{\text {in }}(t)+ \\
& \frac{12 \eta}{A_{g r} \rho C_{P} h} u(t)+\frac{273.15}{A_{g r} \rho C_{P} h}+\frac{c_{1} \tau S_{\text {out }} A_{g r} r i n I^{0}}{V_{a p} c_{p} h}+\frac{T_{l}}{305\left(D / v_{i n}\right)^{0.5} h}+\frac{h_{c} t_{\text {out }} A_{s u}}{A_{g r} \rho C_{P} h}+\frac{T_{s}}{305\left(D / v_{i n}\right)^{0.5} h} \\
& +\frac{T_{h} A_{h} \alpha_{h}}{\rho C_{P} h}+\frac{T_{w} A_{w} \alpha_{w}}{\rho C_{P} h}-\frac{C_{l} R_{n}}{\rho C_{P} h} \\
& \dot{H}_{\text {in }}(t)=\frac{e_{s} \beta}{r \lambda h} T_{\text {in }}(t)-\left(\frac{h_{l} P}{8.036 \gamma \lambda h}+\frac{\phi_{a}}{h}\right) H_{\text {in }}(t)-\frac{\eta A_{r} h_{P}}{A_{g r} \lambda h} u(t)+\frac{\phi_{a}}{h}+\frac{C_{l} R_{n}}{\lambda h} \\
& +\frac{0.00164 A_{r}\left(1+0.378 e_{a} / P\right)^{1 / 3}}{A_{g r} h}\left(T_{i n}(t)-T_{r}\right)^{1 / 3}\left[\frac{2165 e_{a}}{T_{\text {in }}(t)+273.15}-H_{\text {in }}(t)\right]
\end{aligned}
$$

where the system state variable can be selected as:

$$
x(t)=\left[x_{1}(t), x_{2}(t)\right]^{T}=\left[T_{\text {in }} H_{\text {in }}\right]^{T}
$$

The input variables are expressed as follows:

$$
u(t)=Q_{P}
$$

The output variables are obtained as:

$$
y(t)=\left[\begin{array}{ll}
y_{1}(t) & y_{2}(t)
\end{array}\right]^{T}=C x(t)=\left[\begin{array}{ll}
1 & 0 \\
0 & 0
\end{array}\right]\left[\begin{array}{l}
x_{1}(t) \\
x_{2}(t)
\end{array}\right]
$$

\section{Nonlinear Adaptive Control Based on Switching Mechanism}

\subsection{Controller Design Model}

The dynamic model of a northern greenhouse is shown in Equations (20) and (21). The north solar greenhouse model can be re-expressed as:

$$
\begin{gathered}
\dot{x}_{1}(t)=-a_{0} x_{1}(t)+a_{1} x_{2}(t)+a_{2} u(t) \\
\dot{x}_{2}(t)=a_{3} x_{1}(t)-a_{4} x_{2}(t)-a_{5} u(t)+a_{6}\left(x_{1}(t)-10\right)^{1 / 3}\left(\frac{8053.8}{x_{1}(t)+273.15}-x_{2}(t)\right)
\end{gathered}
$$

where,

$$
\begin{aligned}
& a_{0}=\frac{h_{c} A_{s u}}{A_{g r} \rho C_{P} h}+\frac{2}{305 h /\left(D / v_{i n}\right)^{0.5}}+\frac{A_{h} \alpha_{h}}{\rho C_{P} h}+\frac{A_{w w} \alpha_{w}}{\rho C_{P} h}+\frac{e_{s} \beta}{\rho C_{P} h \gamma} \\
& a_{1}=\frac{h_{l} P}{8.036 \gamma \rho C_{P} h}, a_{2}=\frac{12 \eta}{A_{g r} \rho C_{P} h}, a_{3}=\frac{e_{s} \beta}{r \lambda h}, a_{4}=\frac{h_{l} P}{8.036 \gamma \lambda h}+\frac{\varepsilon V_{a}}{3600 h}, \\
& a_{5}=\frac{\eta A_{r} h_{p}}{A_{g r} \lambda h} \text { and } a_{6}=\frac{0.00164 A_{r}\left(1+0.378 e_{a} / P\right)^{1 / 3}}{A_{g r} h} .
\end{aligned}
$$

In this paper, first order Taylor expansion was used to approximate the derivative of $x_{1}$ and $x_{2}$ by discarding the high order error items. The following discrete-time system can approximate the dynamic properties of the continuous greenhouse system.

$$
\begin{gathered}
x_{1}(t+1)=x_{1}(t)+\dot{x}_{1}(t) T \\
x_{2}(t+1)=x_{2}(t)+\dot{x}_{2}(t) T \\
y(t)=x_{1}(t)+\omega(t)
\end{gathered}
$$


where $T$ is the sampling period. $x_{1}(t), x_{2}(t)$ represent corresponding state variables at sampling instants of the continuous system. $\omega(t)$ is the measurement noise.

Substituting Equation (22) into Equation (24), we obtain:

$$
\begin{aligned}
x_{2}(t) & =\frac{x_{1}(t+1)-x_{1}(t)}{a_{1} T}+\frac{a_{0} x_{1}(t)-a_{2} u(t)}{a_{1}} \\
& \triangleq f_{1}(y(t+1), y(t), u(t))
\end{aligned}
$$

Thus,

$$
\begin{gathered}
x_{2}(t-1)=\frac{x_{1}(t)-x_{1}(t-1)}{a_{1} T}+\frac{a_{0} x_{1}(t-1)-a_{2} u(t-1)}{a_{1}} \\
\triangleq f_{1}(y(t), y(t-1), u(t-1))
\end{gathered}
$$

Furthermore, noticing Equations (23), (25) and (28), we obtain:

$$
\begin{aligned}
& x_{2}(t)=x_{2}(t-1)+\dot{x}_{2}(t-1) T=f_{1}\left(x_{1}(t), x_{1}(t-1), u(t-1)\right)+\left\{a_{3} x_{1}(t-1)\right. \\
& \left.-a_{4} x_{2}(t-1)-a_{5} u(t-1)-a_{6}\left(x_{1}(t-1)-10\right)^{1 / 3}\left[\frac{8053.8}{x_{1}(t-1)+273.15}-x_{2}(t-1)\right]\right\} T \\
& \triangleq f_{2}(y(t), y(t-1), u(t-1))
\end{aligned}
$$

Noticing Equations (24) and (26), we obtain:

$$
\begin{aligned}
& y(t+1)=x_{1}(t+1)=x_{1}(t)+\dot{x}_{1}(t) T=x_{1}(t)+\left(-a_{0} x_{1}(t)\right. \\
& \left.+a_{1} f_{2}(y(t), y(t-1), u(t-1))+a_{2} u(t)\right) T \\
& \triangleq f_{3}(y(t), y(t-1), u(t), u(t-1))
\end{aligned}
$$

Applying a similar approach in [42], the greenhouse dynamical model can be decomposed into a linear model incorporating a nonlinear term nearby the operating point, which can be expressed in the following formulation:

$$
A\left(z^{-1}\right) y(t)=B\left(z^{-1}\right) u(t-1)+v(t-1)
$$

where $A\left(z^{-1}\right)=1+a z^{-1}, B\left(z^{-1}\right)=1+b z^{-1} . a$ and $b$ are polynomials about $z^{-1} \cdot n_{a}$ and $n_{b}$ are the system orders. $v[x(t)]=v\left[y(t), \ldots, y\left(t-n_{a}+1\right), u(t), \ldots, u\left(t-n_{b}\right)\right]$ is the higher order nonlinear item.

\subsection{Nonlinear Controller}

Before introducing the nonlinear controller, a linear controller was first introduced based on generalized minimum variance. The control object can be obtained as follows:

$$
A\left(z^{-1}\right) y(t)=B\left(z^{-1}\right) u(t-1)+\omega(t-1)
$$

The generalized minimum variance performance index was introduced in the following function:

$$
J=\left\|y(t+1)-M\left(z^{-1}\right) w(t)+Q\left(z^{-1}\right) u(t)\right\|^{2}
$$

where $M\left(z^{-1}\right)$ and $Q\left(z^{-1}\right)$ are polynomial about $z^{-1}$.

The Diophantine equation was introduced as follows:

$$
1=F A\left(z^{-1}\right)+z^{-1} D\left(z^{-1}\right)
$$

where $F$ is a constant. $D\left(z^{-1}\right)$ is diagonal polynomial matrix.

Substituting Equation (34) into Equation (32) yields:

$$
y(t+1)=D\left(z^{-1}\right) y(t)+F B\left(z^{-1}\right) u(t)+F \omega(t)
$$


Substituting Equation (35) into Equation (33), the generalized minimum variance linear controller can be expressed as follows:

$$
\left[F B\left(z^{-1}\right)+Q\left(z^{-1}\right)\right] u(t)=M\left(z^{-1}\right) w(t)-D\left(z^{-1}\right) y(t)-F \omega(t)
$$

where $H\left(z^{-1}\right)=F B\left(z^{-1}\right)+Q\left(z^{-1}\right)$. The linear feedback controller based on generalized minimum variance is shown in Figure 4.

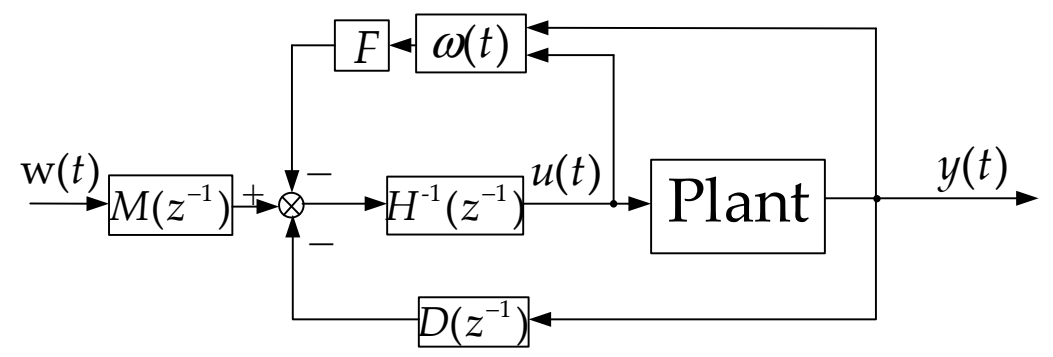

Figure 4. Linear feedback controller based on generalized minimum variance.

However, the linear feedback controller could not meet the actual control requirements when applying it to the complex nonlinear system. In order to control complex dynamic systems better, a nonlinear controller based on generalized minimum variance was constructed in this paper.

In order to effectively control the nonlinear plant (31), the nonlinear controller can be expressed as follows:

$$
u(t)=\bar{L}^{-1}\left(z^{-1}\right)\left[\bar{M}\left(z^{-1}\right) w(t)-\bar{D}\left(z^{-1}\right) y(t)-\bar{K}\left(z^{-1}\right) v(t)\right]
$$

where $\bar{M}\left(z^{-1}\right), \bar{L}\left(z^{-1}\right)$ and $\bar{D}\left(z^{-1}\right)$ are diagonal polynomial matrices. $\bar{K}\left(z^{-1}\right)$, which is a polynomial matrix about $z^{-1}$, is used to eliminate the effect of the nonlinear term $v(t)$, $\bar{L}\left(z^{-1}\right)=1-z^{-1} . w(t)$ is defined as bounded reference input.

Substituting Equation (37) into Equation (31) yields:

$$
\left[\bar{L}\left(z^{-1}\right) A\left(z^{-1}\right)+z^{-1} B\left(z^{-1}\right) \bar{D}\left(z^{-1}\right)\right] y(t+1)=B\left(z^{-1}\right) \bar{M}\left(z^{-1}\right) w(t)+\left[\bar{L}\left(z^{-1}\right)-B\left(z^{-1}\right) \bar{K}\left(z^{-1}\right)\right] v(t)
$$

where $\left[\bar{L}\left(z^{-1}\right) A\left(z^{-1}\right)+z^{-1} B\left(z^{-1}\right) \bar{D}\left(z^{-1}\right)\right], B\left(z^{-1}\right) \bar{M}\left(z^{-1}\right)$, and $\left.\overline{[L}\left(z^{-1}\right)-B\left(z^{-1}\right) \bar{K}\left(z^{-1}\right)\right]$ are diagonal matrices.

The influence of $\left[\bar{L}\left(z^{-1}\right)-B\left(z^{-1}\right) \bar{K}\left(z^{-1}\right)\right] v(t)$ can be removed by making an adequate selection of $\bar{K}\left(z^{-1}\right)$, which implies the influence of nonlinear term $v(t)$.

According to Equation (38), the closed-loop characteristic polynomial of the system is as follows:

$$
T\left(z^{-1}\right)=\bar{L}\left(z^{-1}\right) A\left(z^{-1}\right)+z^{-1} B\left(z^{-1}\right) \bar{D}\left(z^{-1}\right)
$$

According to Equation (38), in order to eliminate the effect of nonlinear term, $\bar{K}\left(z^{-1}\right)$ was chosen to satisfy the following Equation:

$$
\bar{L}\left(z^{-1}\right)=B\left(z^{-1}\right) \bar{K}\left(z^{-1}\right)
$$

The nonlinear control strategy can be seen in Figure 5 . 


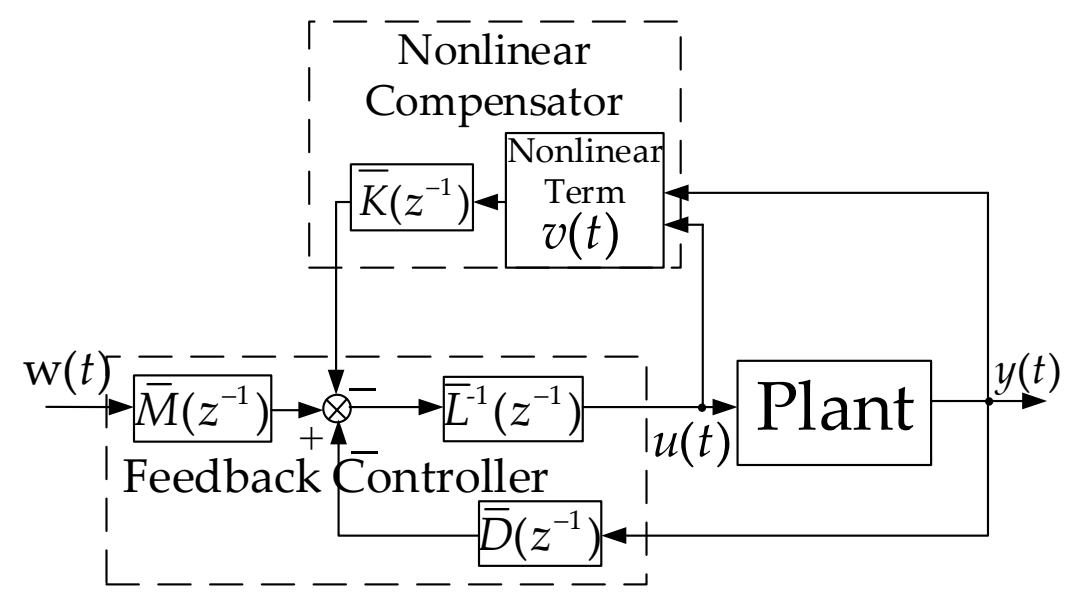

Figure 5. Nonlinear control strategy.

\subsection{Parameters Selection}

In order to identify parameters of the controller (37), the following cost function was introduced:

$$
\psi=\left\|y(t+1)-M\left(z^{-1}\right) w(t)+Q\left(z^{-1}\right) u(t)+K\left(z^{-1}\right) v(t)\right\|^{2}
$$

where $M\left(z^{-1}\right), Q\left(z^{-1}\right), K\left(z^{-1}\right)$ are polynomial about $z^{-1}$.

The following Diophantine equation was introduced:

$$
1=F A\left(z^{-1}\right)+z^{-1} D\left(z^{-1}\right)
$$

Substituting Equation (42) into Equation (31) yields:

$$
y(t+1)=D\left(z^{-1}\right) y(t)+F B\left(z^{-1}\right) u(t)+F v(t)
$$

Substituting Equation (43) into Equation (41), if the performance index is $\psi=0$, the generalized minimum variance controller can be obtained as follows:

$$
\left[F B\left(z^{-1}\right)+Q\left(z^{-1}\right)\right] u(t)=M\left(z^{-1}\right) w(t)-D\left(z^{-1}\right) y(t)-\left[F+K\left(z^{-1}\right)\right] v(t)
$$

A constant $\lambda$ is introduced, we selected $\lambda$ which satisfied the performance index of Equation (41).

$$
\begin{gathered}
M\left(z^{-1}\right)=\lambda^{-1} \bar{M}\left(z^{-1}\right) \\
Q\left(z^{-1}\right)=\lambda^{-1} \bar{L}\left(z^{-1}\right)-F B\left(z^{-1}\right) \\
K\left(z^{-1}\right)=\lambda^{-1} \bar{L}\left(z^{-1}\right) B^{-1}\left(z^{-1}\right)-F \\
\operatorname{det}\left\{\bar{L}\left(z^{-1}\right) A\left(z^{-1}\right)+z^{-1} \lambda B\left(z^{-1}\right) D\left(z^{-1}\right)\right\} \neq 0,|z|<1
\end{gathered}
$$

\subsection{Adaptive Switching Control}

The parameters of the greenhouse model always vary as the external environment changes. These situations directly lead to the occurrence of parameter uncertainties. Therefore, it is necessary to update model parameters of CSG in real time. According to Equation (37), the following formula is given to identify the system parameters: $y(t)=$ $\theta^{T} X(t-1)+v(t-1)$, where $X(t-1)=\left[y(t-1), \ldots, y\left(t-n_{a}\right), u(t-1), u\left(t-n_{b}-1\right)\right]$, $\theta=\left[-a_{1}, \ldots,-a_{n}, b_{0}, \ldots, b_{n_{b}}\right]$. 
To predict the output of the system, two estimation models were introduced in this paper. The first one was the linear estimation model:

$$
\hat{y}_{1}(t)=\hat{\theta}_{1}^{T}(t-1) X(t-1)
$$

where $\theta$ can be approximated as $\hat{\theta}_{1}^{T}(t-1)$ at instant $t-1$ and the parameter $\theta$ can be determined through the algorithm as follows:

$$
\begin{gathered}
\hat{\theta}_{1}(t)=\hat{\theta}_{1}(t-1)+\frac{\mu_{1}(t) X(t-1) e_{1}^{T}(t)}{1+X(t-1)^{T} X(t-1)} \\
\mu_{1}(t)=\left\{\begin{array}{cc}
1 & \text { if }\left\|e_{1}(t)\right\|>4 \triangle \\
0 & \text { else }
\end{array}\right.
\end{gathered}
$$

where $\triangle>0$ is the upper bound of the nonlinear term $v(t-1)$. The linear model error $e_{1}(t)$ is defined as follows:

$$
e_{1}(t)=y(t)-\hat{y}_{1}(t)=y(t)-\hat{\theta}_{1}^{T}(t-1) X(t-1)
$$

The neural network nonlinear estimation model, written in the following algorithm, is the second model.

$$
\hat{y}_{2}(t)=\hat{\theta}_{2}^{T}(t-1) X(t-1)+\hat{v}(t-1)
$$

where $\hat{v}(t-1)$ is approximated through RBF neural networks and $\hat{\theta}_{2}^{T}(t-1)$ is the second approximation of $\theta$ at instant $t-1$. The algorithm was employed to identify the parameter as follows:

$$
\begin{gathered}
\hat{\theta}_{2}(t)=\hat{\theta}_{2}(t-1)+\frac{\beta(t) X(t-1) e_{2}^{T}(t)}{1+X(t-1)^{T} X(t-1)} \\
\beta(t)=\left\{\begin{array}{cc}
1 & \text { if }\left\|e_{2}(t)\right\|>4 \xi \\
0 & \text { else }
\end{array}\right.
\end{gathered}
$$

where $|v(t-1)-\hat{v}(t-1) \leq \xi|, \xi<0$ is a pre-specified small positive number and $e_{2}(t)$ is the nonlinear model error, i.e.:

$$
e_{2}(t)=y(t)-\hat{y}_{2}(t)=y(t)-\hat{\theta}_{2}^{T}(t-1) X(t-1)-\hat{v}(t-1)
$$

Without considering nonlinear term $\hat{v}(t-1)$, the linear adaptive control law based on the linear estimation model can be expressed in the following Equation:

$$
\bar{L}\left(z^{-1}\right) u(t)=\hat{\bar{M}}_{1}^{t} w(t)-\hat{\bar{D}}_{1}^{t} y(t)
$$

From Equation (31), the nonlinear adaptive control law based on the RBF neural network nonlinear estimation model is expressed as follows and the structure is shown in Figure 6.

$$
\bar{L}\left(z^{-1}\right) u(t)=\hat{\bar{M}}_{2}^{t}\left(z^{-1}\right) w(t)-\hat{\bar{D}}_{2}^{t}\left(z^{-1}\right) y(t)-\hat{\bar{K}}_{2}^{t}\left(z^{-1}\right) \hat{v}(t)
$$




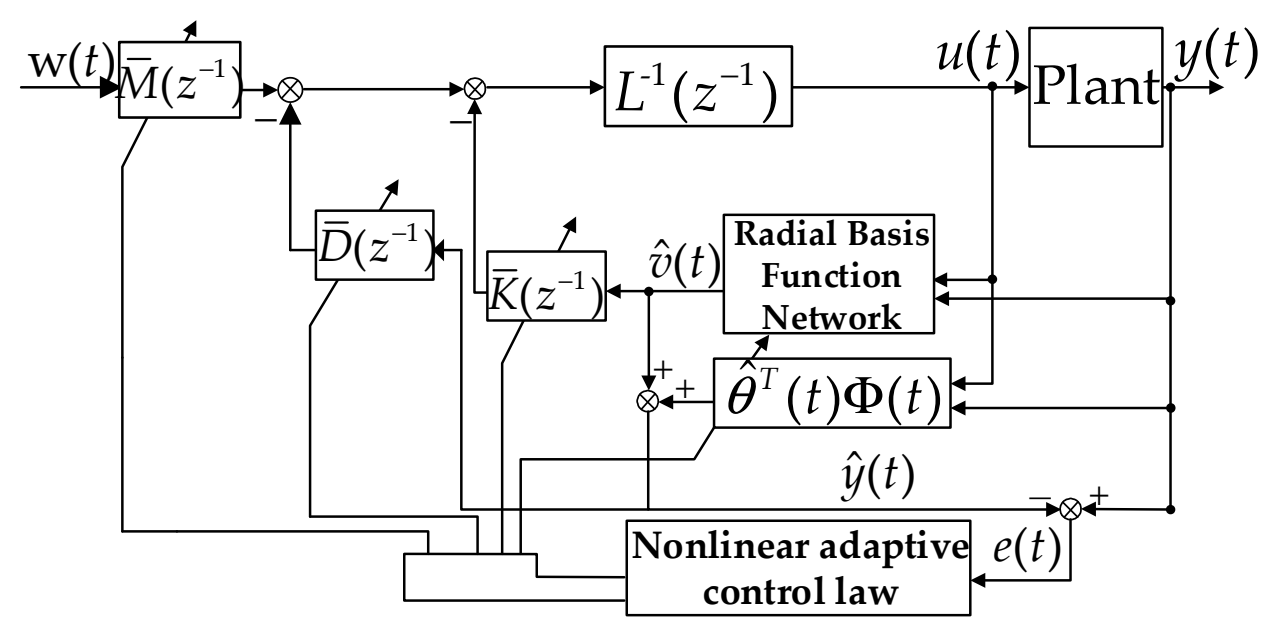

Figure 6. Nonlinear adaptive controller structure.

To ensure the stability of the close-loop system, the linear adaptive controller was adopted in this paper. However, the strong nonlinear system showed poor performance if a nonlinear item $\hat{v}(t-1)$ was larger when using a linear adaptive controller alone. The nonlinear adaptive controller can decrease the effect of a nonlinear term on system output. However, the nonlinear adaptive controller has an aggressive control effect and stability of the close-loop system cannot be guaranteed. In this paper, a switching mechanism was introduced to enhance performance of the control system and guarantee stability for the closed-loop system, which is shown in Figure 7. The switching criterion is defined as:

$$
\begin{gathered}
J_{i}(t)=\sum_{l=1}^{t} \frac{\mu_{i}(l)\left(\left\|e_{i}(l)\right\|^{2}-16 \Delta^{2}\right)}{4\left(1+X(l-1)^{T} X(l-1)\right)}+\alpha \sum_{l=t-N+1}^{t}\left(1-\mu_{i}(l)\right)\left\|e_{i}(l)\right\|^{2} \quad(i=1.2) \\
\mu_{i}(t)= \begin{cases}1 & \text { if }\left\|e_{i}(t)\right\|>4 \Delta \\
0 & \text { else }\end{cases}
\end{gathered}
$$

where $N$ is an integer and $\alpha \geq 0$ is a predefined constant, $i=1$ denotes the linear model, and $i=2$ stands for the nonlinear models. Each time, $t$, the nonlinear estimation model, and the linear model predicted the system output, and model parameters were automatically updated by the identified algorithm. Meanwhile, $J_{1}(t)$ and $J_{2}(t)$ were calculated respectively and the control law $u^{*}(t)$ was selected corresponding to the smaller $J^{*}(t)$ to control the system.

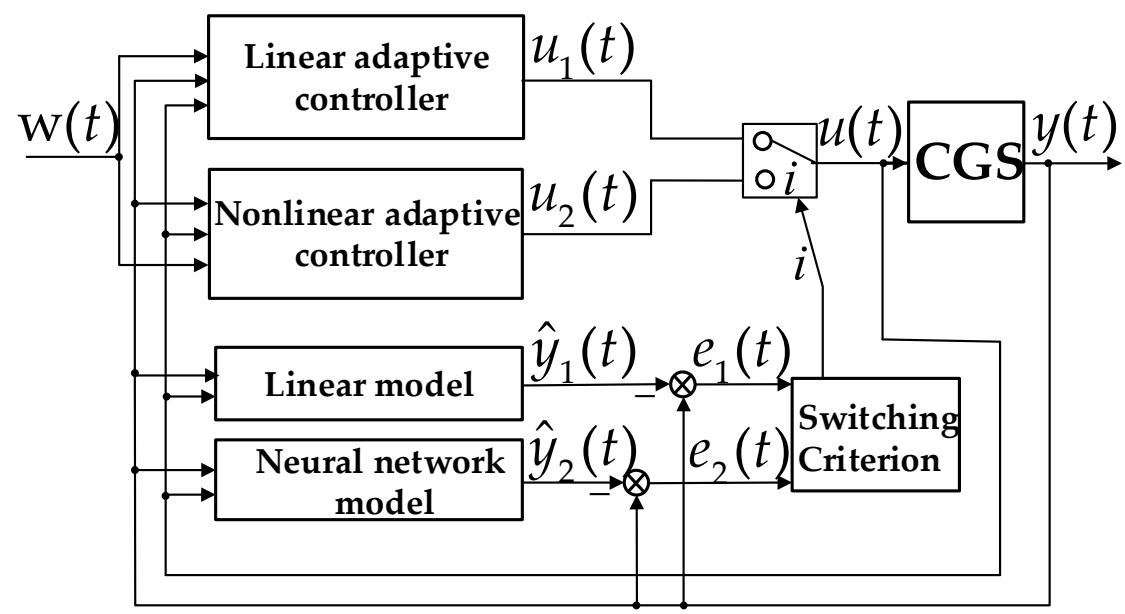

Figure 7. Switching mechanism based on multiple model. 


\subsection{RBF Neural Network for Unmodeled Dynamics}

As we all know, neural networks are capable of approaching a complicated nonlinear mapping sufficiently owing to the rich connections and nonlinear activating functions of neurons [43]. In this research, an RBF network was employed to estimate and compensate the unmodeled dynamics of the CSG system.

The RBF neural network was divided into three layers herein in this paper, the input layer which connects the input vector to the network, the unique hidden layer, and the output layer. The activation function of RBF neural network was the Gaussian function, which can be expressed as [44]:

$$
F(x)=\exp \left(\frac{\|x-c\|^{2}}{2 \sigma^{2}}\right)
$$

where $x$ is the $n$-dimensional input vector and $c$ is the center vector, which is the same as the $x$-dimension, and $\sigma$ is the width of the basis function around the center point.

In this paper, the output of the neural network input layer was $\hat{v}_{i}[x(t)]$. The input vector was $x(t)=\left[y(t), \ldots, y\left(t-n_{a}+1\right), u(t), \ldots, u\left(t-n_{b}\right)\right]$, and the output layer network nonlinear output was as follows:

$$
\hat{v}_{i}[x(t)]=\sum_{p=1}^{q} W_{p m} F_{p}(x)
$$

where, $m=1,2, \ldots, l$ and $q$ is the number of nodes in the hidden layer, $l$ is the number of nodes in the output layer, $W_{p m}$ is the connection weight between the neuron $P$ in the hidden layer and the neuron $\mathrm{m}$ in the output layer, and $F_{p}(x)$ is the excitation function of the neuron $P$ in the hidden layer.

\section{Results}

In this part, two simulation experiments, being composed of a set-point tracking experiment and a full-day real weather experiment, were conducted to test the performance of the nonlinear adaptive control strategy.

\subsection{Set-Point Tracking Experiment}

The research was designed to prove the effectiveness of the control method for CSG in terms of the tracking performance with strong multi-disturbances. There existed internal conditions as follows: solar radiation $S_{\text {out }}=350 \mathrm{~W} / \mathrm{m}^{2}$, outside air temperature $t_{\text {out }}=5^{\circ} \mathrm{C}$, outside humidity $H_{\text {out }}=16 \mathrm{~g} / \mathrm{m}^{3}$, outside wind speed $v_{\text {out }}=2 \mathrm{~m} / \mathrm{s}$, inside temperature $t_{\text {in }}=17{ }^{\circ} \mathrm{C}$, and inside humidity $H_{\text {in }}=18 \mathrm{~g} / \mathrm{m}^{3}$. After using the Euler method, the initial design models were expressed around the nominal operating point as follows: $A\left(z^{-1}\right)=1-1.992 z^{-1}+0.9851 z^{-2}, B\left(z^{-1}\right)=0.004321-0.4223 z^{-1}$, where the system order was $n_{a}=2$ and $n_{b}=1$. In this situation $\lambda$ was chosen as 0.2 and the switching criterion parameters were selected to be $\alpha=1, N=2$, and $\Delta=0.015$. The initial weights of the RBF neural network were obtained by training the input and output data in a small range of working points. The hidden layer was equal to 8 and the relevant parameters were chosen to be $q=6, \sigma=0.65, \alpha=0.05$, and $\eta_{R B F}=0.3$.

In order to research the tracking performance of the nonlinear adaptive controller, the inside temperature set points were changed to a wide range. At the same time, the outside weather conditions, such as outside temperature, outside wind speed, and outside solar radiation fluctuated in a large scope. The experiment design was as follows. The inside temperature was changed from $17^{\circ} \mathrm{C}$ to $28^{\circ} \mathrm{C}$ at $\mathrm{t}=0-500 \mathrm{~s}$. The effects of the external disturbances were simulated in this process. The outside temperature was changed from $5^{\circ} \mathrm{C}$ to $-3^{\circ} \mathrm{C}$ at $\mathrm{t}=150 \mathrm{~s}$. The solar radiation was changed from $350 \mathrm{~W} / \mathrm{m}^{2}$ to $150 \mathrm{~W} / \mathrm{m}^{2}$ at $\mathrm{t}=350 \mathrm{~s}$. The inside temperature was changed from $28^{\circ} \mathrm{C}$ to $24{ }^{\circ} \mathrm{C}$ at $\mathrm{t}=500 \mathrm{~s}$ and the outside solar radiation simultaneously became zero. The outside wind speed was changed 
from $2 \mathrm{~m} / \mathrm{s}$ to $6 \mathrm{~m} / \mathrm{s}$ at $\mathrm{t}=700 \mathrm{~s}$ and the outside temperature was changed from $-3{ }^{\circ} \mathrm{C}$ to $-12{ }^{\circ} \mathrm{C}$ at $\mathrm{t}=850 \mathrm{~s}$. In the end, the inside temperature was changed from $24^{\circ} \mathrm{C}$ to $19{ }^{\circ} \mathrm{C}$ at $\mathrm{t}=1000 \mathrm{~s}$. The effect of the extreme outside temperature was simulated during this period. The outside temperature was changed from $-16^{\circ} \mathrm{C}$ to $-27^{\circ} \mathrm{C}$ at $\mathrm{t}=1200 \mathrm{~s}$.

The set-point tracking research results are demonstrated in Figures 8 and 9. The inside temperature quickly tracked the set point and the control method reduced the influence of uncertain factors. Moreover, in the face of strong external disturbances such as stiff wind and cold weather, the inside temperature still tracked the set point quickly.



Figure 8. Response of inside temperature.

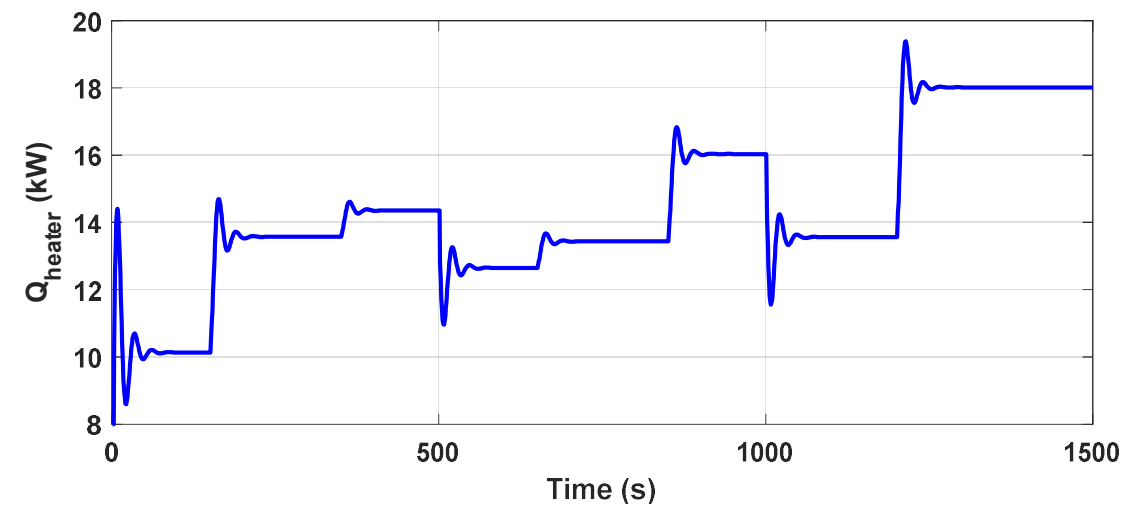

Figure 9. Corresponding control input.

\subsection{Full-Day Real Weather Experiment}

In this test, we used experimental data from a full, cold day (26 January 2018) in Shenyang, China. The environmental conditions (including inside temperature, outside wind, outside humidity, outside temperature, and solar radiation) from 0:00 to 24:00 were collected every $15 \mathrm{~min}$. Figures 10-14 express the inside temperature, wind speed, outside humidity, outside temperature and solar radiation, respectively. It can be derived from Figures 10-14 that the aforementioned model parameters show random properties. Figure 10 shows that the inside temperature exceeded $15^{\circ} \mathrm{C}$ from 9:30 to $16: 00$ on 26 January 2018, and at other times was below $15{ }^{\circ} \mathrm{C}$, which was unfavorable for crop growth. We determined the set point of the inside temperature according to the following rules. Firstly, the set point was designed according to the current temperature of the greenhouse. The air heater equipment shut off when the current temperature exceeded $20^{\circ} \mathrm{C}$. Secondly, the set point of the temperature was adjusted by the energy management. The set point gradually decreased to $15^{\circ} \mathrm{C}$ with the reduction of outside solar radiation, which met the minimum requirement for the crops. The set point curve of the temperature is shown in Figure 10 (red line). The air heater equipment was turned on and off at 15:30 and 10:00, respectively. The outside weather data were substituted into the dynamical model of the 
CSG during the experiment. The corresponding response for the set point of the inside temperature is shown in Figure 15. The corresponding response of control input is shown in Figure 16. The tracking error curves, corresponding to the conventional PID method and the presented nonlinear adaptive scheme, are shown in Figures 17 and 18.

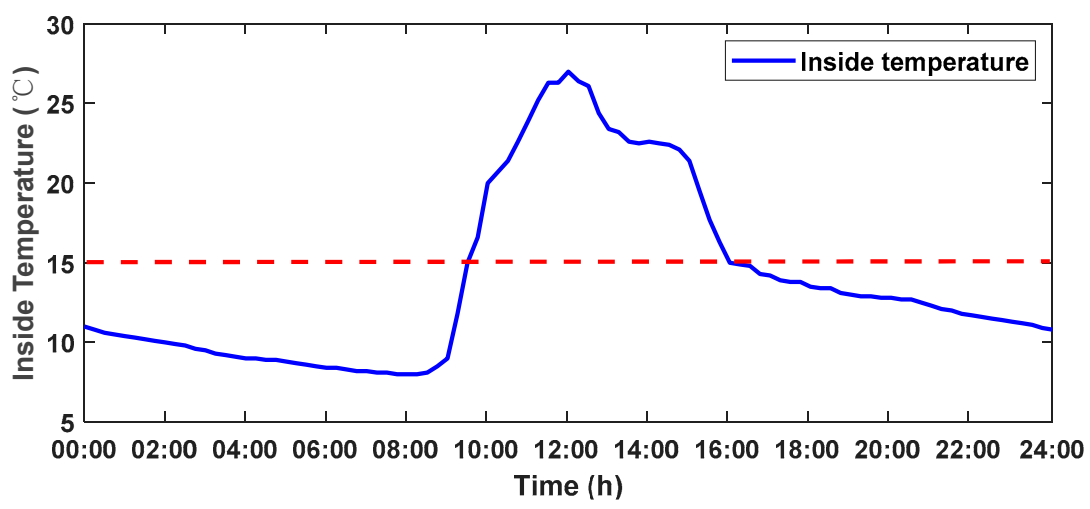

Figure 10. The inside temperature of the CSG on 26 January 2018.

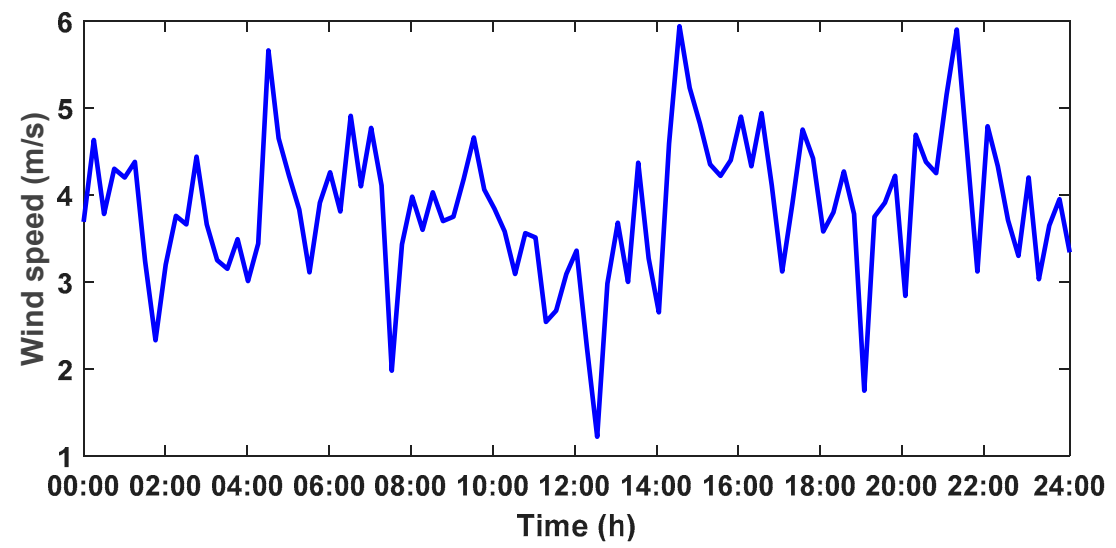

Figure 11. The outside wind speed of the CSG on 26 January 2018.

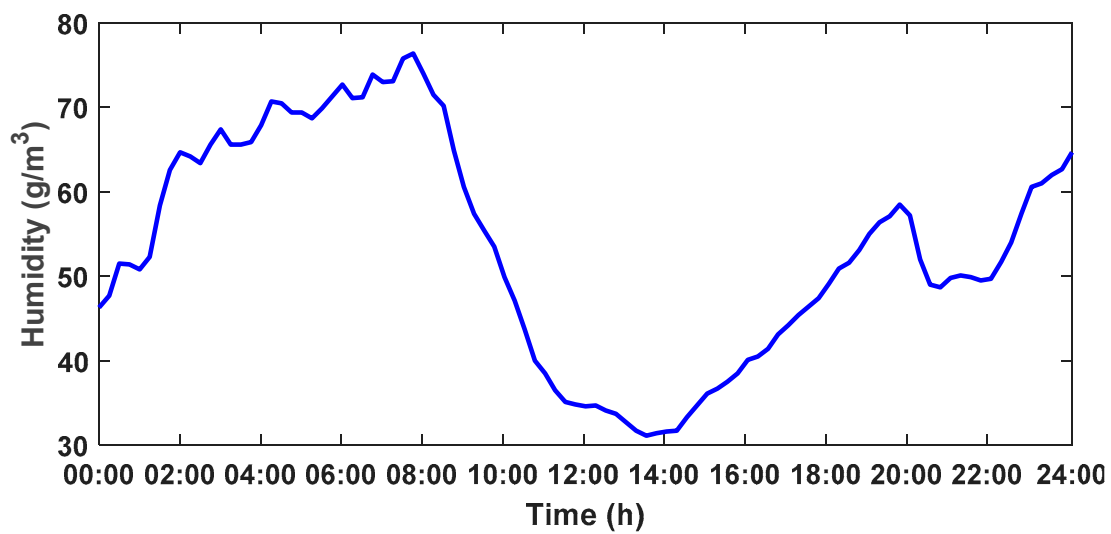

Figure 12. The outside humidity of the CSG on 26 January 2018. 


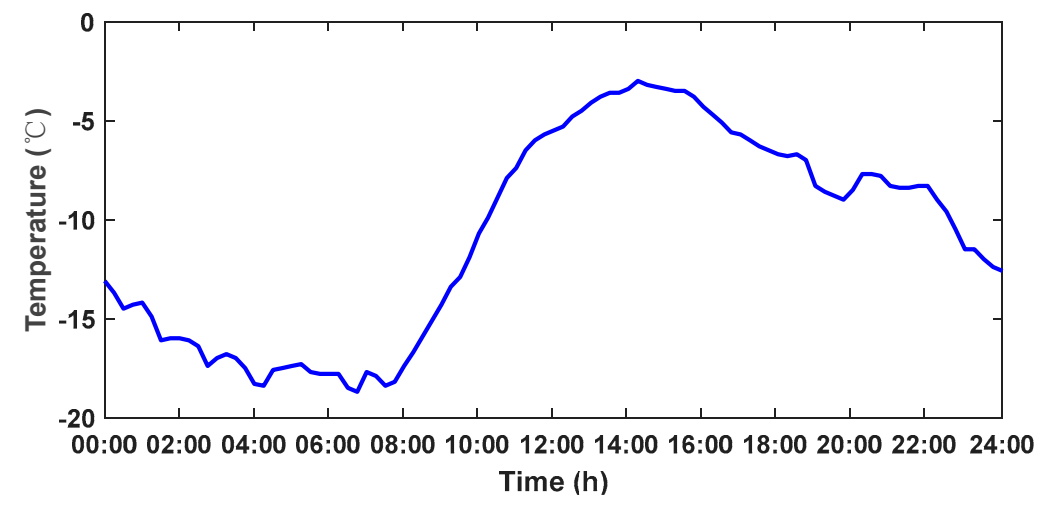

Figure 13. The outside temperature of the CSG on 26 January 2018.

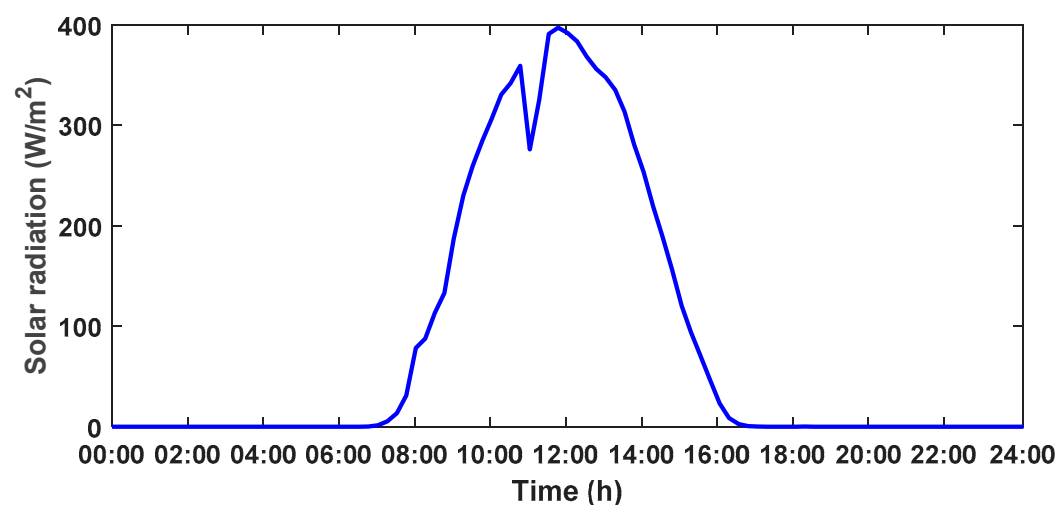

Figure 14. The outside solar radiation of the CSG on 26 January 2018.

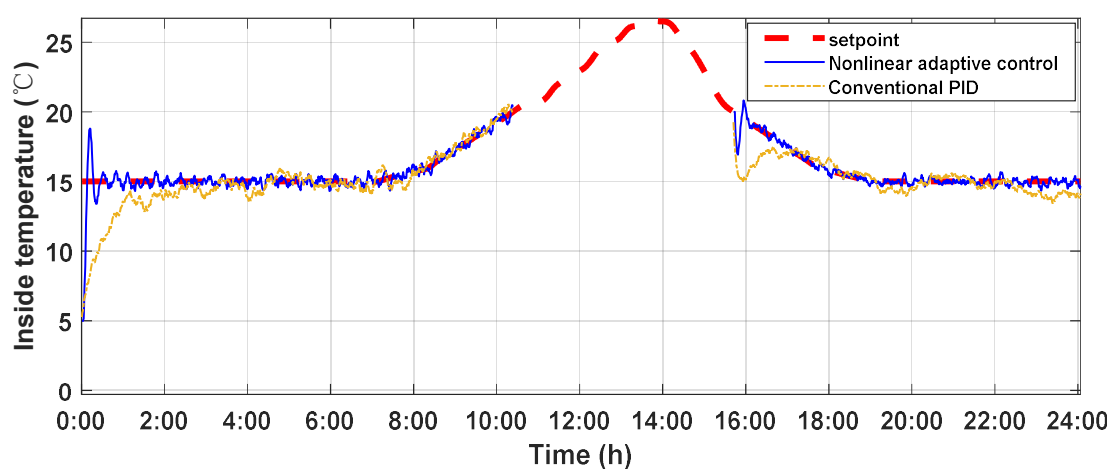

Figure 15. The corresponding response for set point of inside temperature.

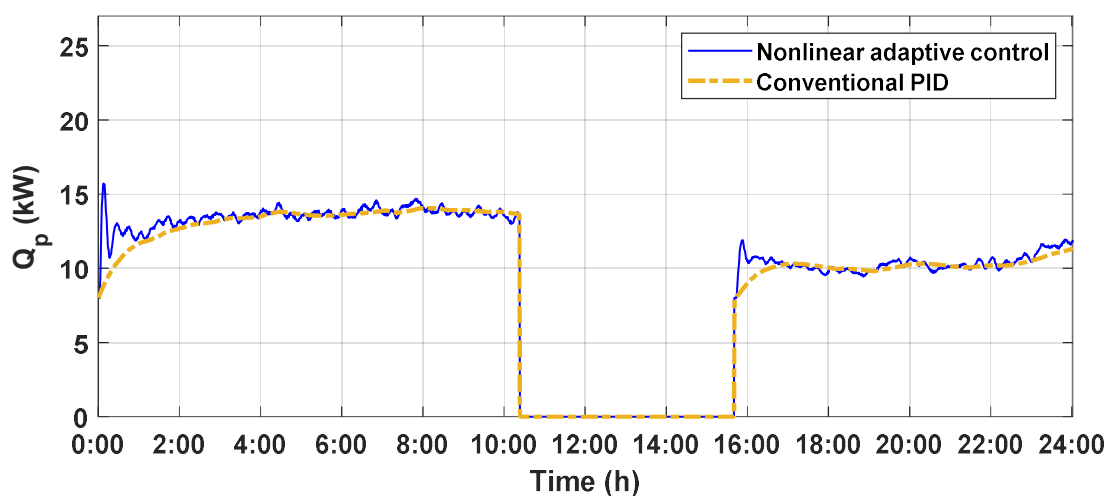

Figure 16. The corresponding response of control input. 


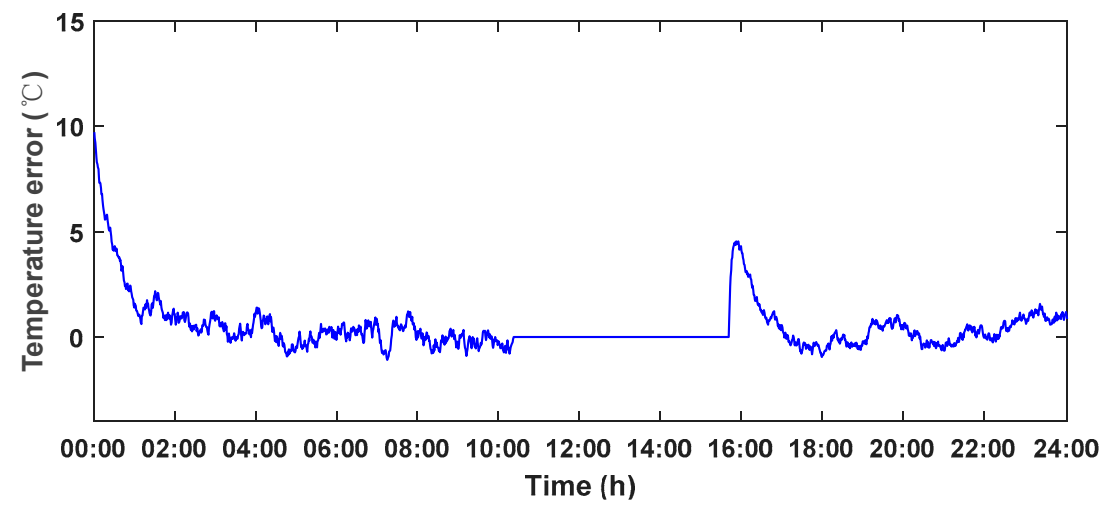

Figure 17. Variation errors of conventional PID control during the experimental process.

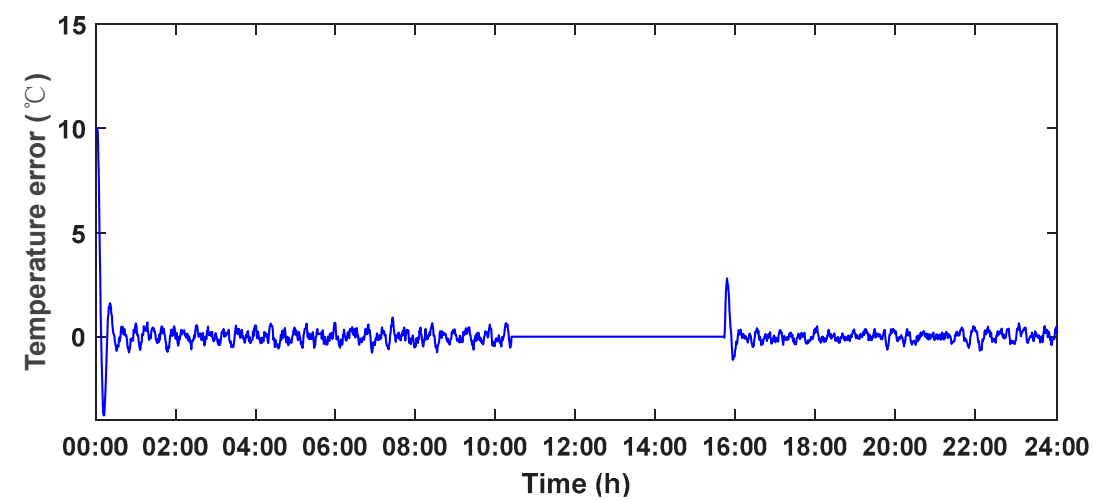

Figure 18. Variation errors of nonlinear adaptive control errors during the experimental process.

As indexes of the variable randomness, average error and standard error were selected to measure the control performance of using a conventional PID method and an RBF nonlinear adaptive scheme. Table 1 shows the consequence of using the conventional PID method and the presented nonlinear adaptive strategy. The mean errors were 0.8460 and 0.2967 , respectively. The standard errors were 1.8480 and 1.3342 , respectively. Moreover, as can be seen from Figures 17 and 18, the tracking error of temperature for the presented nonlinear control scheme was smaller than the error of the conventional PID method. By comparing the two methods, it can be seen that the presented nonlinear adaptive control scheme showed better control performance, characterized by good adaptability and preferable robustness. Compared to the conventional PID method, the proposed nonlinear adaptive scheme has the following advantages. Firstly, the strategy improves set-point tracking performance greatly and is more robust. Secondly, it has a better adaptability for external climatic disturbance. Thirdly, it may give a meaningful reference to deal with the complex greenhouse climate control problem.

Table 1. Performance Comparison between conventional PID control and nonlinear RBF adaptive control.

\begin{tabular}{cccc}
\hline \multirow{2}{*}{ Methods } & \multicolumn{2}{c}{ Temperature Error $\left({ }^{\circ} \mathbf{C}\right)$} & \multirow{2}{*}{ Corresponding Line Front } \\
\cline { 2 - 3 } & Mean & Standard & \\
\hline $\begin{array}{c}\text { Conventional PID } \\
\text { Nonlinear adaptive } \\
\text { control }\end{array}$ & 0.8460 & 1.8480 & orange, dash-dot \\
& 0.2967 & 1.3342 & blue, solid \\
\hline
\end{tabular}

\section{Conclusions}

In this paper, the CSG has been described as a nonlinear, uncertain and multidisturbance dynamic system. A nonlinear dynamic model for CSGs, based on energy 
conservation laws, was constructed by equations, and the corresponding control model was established. A nonlinear adaptive control strategy for CSG production, employing an RBF neural network, was proposed. The main objective was to meet the normal requirements of temperature control for CSGs. Due to the great ability to deal with a non-minimum phase system, a generalized minimum variance method was introduced to determine the controllers' parameters. Considering the strong learning capacity of the RBF neural network, the RBF neural network was employed to estimate and compensate the unmodeled dynamics of the system. The mean error and standard error for the conventional PID method were 0.8460 and 1.8480, respectively. By contrast, the presented nonlinear control strategy had great improvement with the result of 0.2967 and 1.3342 , corresponding to the mean and standard error. The control strategy was tested for complex greenhouse climate control and the experiment results showed that the presented nonlinear adaptive control method had great adaptability, robustness, and prominent real-time control performance. A valuable reference can be provided by this control method to formulate climate control schemes for practical application in greenhouse production.

Author Contributions: Y.W., Y.L. and R.X. conceived and designed the experiments; Y.W. and Y.L. performed the experiments; Y.W. and Y.L. analyzed the data; Y.W. and Y.L. supervised the experiment; Y.W. and Y.L. wrote the manuscript; Y.W., Y.L. and R.X. reviewed the manuscript. All authors have read and agreed to the published version of the manuscript.

Funding: This project was supported by the National Natural Science Foundation of China (NSFC) (61673281,32001415,61903264) and the Natural Science Foundation of Liaoning Province (2019-KF-03-01).

Data Availability Statement: Data is contained within the article.

Acknowledgments: The authors sincerely thank the National Natural Science Foundation of China for their financial support. We gratefully acknowledge the assistance of Tan Liu, Qingyun Yuan, Dapeng Zhang, Nannan Zhang in revised manuscript. We are also grateful to reviewers for their recommendations to improve the quality of this paper.

Conflicts of Interest: The authors declare no conflict of interest.

\section{Appendix A}

Table A1. Meanings of parameters of the greenhouse temperature model.

\begin{tabular}{|c|c|c|c|}
\hline Parameter & Meaning & Value Range & Unit \\
\hline $\mathrm{P}$ & standard atmospheric pressure & 101 & $\mathrm{kPa}$ \\
\hline$\rho$ & air density & 1.1691 & $\mathrm{~kg} / \mathrm{m}^{3}$ \\
\hline$C_{P}$ & the specific heat of air at constant pressure & 1.003 & - \\
\hline$e_{S}$ & the air saturation vapor pressure & 3.167 & $\mathrm{kPa}$ \\
\hline$\gamma$ & the psychrometric constant & 66 & $\mathrm{~Pa} /{ }^{\circ} \mathrm{C}$ \\
\hline$\lambda$ & latent heat of evaporation & 2450 & $\mathrm{~J} / \mathrm{g}$ \\
\hline$v_{\text {out }}$ & outside wind speed & $0.2-12$ & $\mathrm{~m} / \mathrm{s}$ \\
\hline$C_{l}$ & the coefficient of convective heat loss from indoor air to the cover & $(0.05-50)$ & - \\
\hline$\eta$ & heat energy efficiency of the heating equipment & 0.85 & - \\
\hline$R_{n}$ & the net solar radiation absorbed by crops & $100-350$ & $\mathrm{~W} / \mathrm{m}^{2}$ \\
\hline$\beta$ & $\begin{array}{c}\text { influence coefficient of temperature change on saturated water vapor } \\
\text { pressure }\end{array}$ & 0.001 & - \\
\hline$H_{\text {out }}$ & outside humidity & $6-29$ & $\mathrm{~g} / \mathrm{m}^{3}$ \\
\hline$A_{w}$ & north wall area & 50 & $\mathrm{~m}^{2}$ \\
\hline$t_{w}$ & north wall temperature & $8-20$ & ${ }^{\circ} \mathrm{C}$ \\
\hline$\alpha_{w}$ & convective heat transfer coefficient through north wall & $5-25$ & - \\
\hline$h_{l}$ & the heat transfer constant between crops and inside air & 13.3 & - \\
\hline$D$ & leaf width & $0.15-0.25$ & $\mathrm{~m}$ \\
\hline
\end{tabular}


Table A1. Cont.

\begin{tabular}{|c|c|c|c|}
\hline Parameter & Meaning & Value Range & Unit \\
\hline$\varepsilon$ & cold air permeability coefficient & $0.2-0.5$ & $\mathrm{~m} / \mathrm{s}$ \\
\hline$\tau$ & the greenhouse global transmission & 0.6 & - \\
\hline$A_{g r}$ & surface area which absorbs solar radiation & 392 & $\mathrm{~m}^{2}$ \\
\hline$A_{\text {su }}^{\circ}$ & the superficial area of the cover materials & 615 & $\mathrm{~m}^{2}$ \\
\hline$h$ & the height of greenhouse & 2.5 & $\mathrm{~m}$ \\
\hline$A_{h}$ & the area of north roof & 100 & $\mathrm{~m}^{2}$ \\
\hline$t_{h}$ & north roof temperature & $8-25$ & ${ }^{\circ} \mathrm{C}$ \\
\hline$c_{1}$ & the aging coefficient of lighting material & 0.82 & - \\
\hline$S_{\text {out }}$ & solar radiation & $100-500$ & $\mathrm{~W} / \mathrm{m}^{2}$ \\
\hline$v_{\text {in }}$ & inside wind speed & $0-0.3$ & $\mathrm{~m} / \mathrm{s}$ \\
\hline$t_{S}$ & soil surface temperature & $6-25$ & ${ }^{\circ} \mathrm{C}$ \\
\hline$t_{l}$ & the leaf temperature of crops & $6-20$ & ${ }^{\circ} \mathrm{C}$ \\
\hline$\alpha_{h}$ & convective heat transfer coefficient through north roof & $5-25$ & - \\
\hline$t_{\text {out }}$ & outside air temperature & $-30-8$ & ${ }^{\circ} \mathrm{C}$ \\
\hline
\end{tabular}

\section{References}

1. Gruber, J.K.; Guzmán, J.L.; Rodríguez, F.; Bordons, C.; Berenguel, M.; Sánchez, J.A. Nonlinear MPC based on a Volterra series model for greenhouse temperature control using natural ventilation. Control Eng. Pract. 2010, 19, 354-366. [CrossRef]

2. Elanchezhian, A.; Basak, J.K.; Park, J.; Khan, F.; Okyere, F.G.; Lee, Y.; Bhujel, A.; Lee, D.; Sihalath, T.; Kim, H.T. Evaluating different models used for predicting the indoor microclimatic parameters of a greenhouse. Appl. Ecol. Environ. Res. 2020, 18, $2141-2161$. [CrossRef]

3. Van Straten, G.; Van Henten, E.J.; Van Willigenburg, L.G.; VanOoteghem, R.J.C. Optimal Control of Greenhouse Cultivation, 1st ed.; CRC Press Inc.: New York, NY, USA, 2010.

4. Tong, G.; Christopher, D.M.; Li, B. Numerical modelling of temperature variations in a Chinese solar greenhouse. Comput. Electron. Agric. 2009, 68, 129-139. [CrossRef]

5. Amitav, B. Changing Climate and Resource Use Efficiency in Plants, 1st ed.; Bhattacharya, A., Ed.; Academic Press: San Diego, CA, USA, 2019; pp. 1-50.

6. Guo, Y.; Zhao, H.; Zhang, S.; Wang, Y.; Chow, D. Modeling and optimization of environment in agricultural greenhouses for improving cleaner and sustainable crop production. J. Clean. Prod. 2020, 285, 124843. [CrossRef]

7. He, Y.; Liang, M.; Chen, L.; Qiao, X.; Du, S. Greenhouse modelling and control based on T-S model. IFAC Pap. 2018, 51, 802-806.

8. Sagrado, J.D.; Sánchez, J.A.; Rodríguez, F.; Berenguel, M. Bayesian networks for greenhouse temperature control. J. Appl. Logic. 2016, 17, 25-35. [CrossRef]

9. Pérez-González, A.; Begovich-Mendoza, O.; Ruiz-León, J. Modeling of a greenhouse prototype using PSO and differential evolution algorithms based on a real-time LabView ${ }^{\mathrm{TM}}$ application. Appl. Soft Comput. 2018, 62, 86-100. [CrossRef]

10. Yang, H.; Liu, Q.; Yang, H. Deterministic and stochastic modelling of greenhouse microclimate. Syst. Sci. Control Eng. 2019, 7 , 65-72. [CrossRef]

11. Li, Q.; Zhang, D.; Ji, J.; Sun, Z.; Wang, Y. Modeling of natural ventilation using a hierarchical fuzzy control system for a new energy- saving solar greenhouse. Appl. Eng. Agric. 2018, 34, 953-962. [CrossRef]

12. Åström, K.J.; Hägglund, T. PID Controllers: Theory, Design and Tuning, 2nd ed.; Instrument Society of America: Research Triangle, NC, USA, 1995.

13. Su, Y.; Xu, L.; Erik, D.G. Greenhouse climate fuzzy adaptive control considering energy saving. Int. J. Control Autom. Syst. 2017, 15, 1936-1948. [CrossRef]

14. Morteza, T.; Yahya, A.; Seyed, F.R.; Abbas, R.; Mansour, M. Heat transfer and MLP neural network models to predict inside environment variables and energy lost in a semi-solar greenhouse. Energy Build. 2016, 110, 314-329.

15. Jang, Y.; Goto, E.; Ishigami, Y.; Mun, B.; Chun, C. Effects of light intensity and relative humidity on photosynthesis, growth and graft-take of grafted cucumber seedlings during healing and acclimatization. Hortic. Environ. Biotechnol. 2011, 52, 331. [CrossRef]

16. Wang, L.; Zhang, H. An adaptive fuzzy hierarchical control for maintaining solar greenhouse temperature. Comput. Electron. Agric. 2018, 155, 251-256. [CrossRef]

17. Chen, L.; Du, S.; Liang, M.; He, Y. Adaptive Feedback Linearization-based Predictive Control for Greenhouse Temperature. IFAC Pap. 2018, 51, 784-789.

18. MontoyaRíos, A.P.; GarcíaMañas, F.; Guzmán, J.L.; Rodríguez, F. Simple Tuning Rules for Feedforward Compensators Applied to Greenhouse Daytime Temperature Control Using Natural Ventilation. Agronomy 2020, 10, 1327. [CrossRef]

19. Tanaya, C.; Yeng, C.S.; Li, H.; Xie, L. A feedforward neural network based indoor-climate control framework for thermal comfort and energy saving in buildings. Appl. Energy 2019, 248, 44-53.

20. Christelle, L.; Thierry, S.; Laurent, L.; Roger, A. Optimal release strategies for the biological control of aphids in melon greenhouses. Biol. Control 2008, 48, 12-21. 
21. Jin, C.; Mao, H.; Chen, Y.; Shi, Q.; Wang, Q.; Ma, G.; Liu, Y. Engineering-oriented dynamic optimal control of a greenhouse environment using an improved genetic algorithm with engineering constraint rules. Comput. Electron. Agric. 2020, 177, 105698. [CrossRef]

22. Rim, B.A.; Salwa, B.; Abdelkader, M. Development of a Fuzzy Logic Controller applied to an agricultural greenhouse experimentally validated. Appl. Therm. Eng. 2018, 141, 798-810.

23. Revathi, S.; Sivakumaran, N. Fuzzy Based Temperature Control of Greenhouse. IFAC Pap. 2016, 49, 549-554. [CrossRef]

24. Chen, L.; Du, S.; He, Y.; Liang, M.; Xu, D. Robust model predictive control for greenhouse temperature based on particle swarm optimization. Inf. Process. Agric. 2018, 5, 329-338. [CrossRef]

25. Bennis, N.; Duplaix, J.; Enéa, G.; Haloua, M.; Youlal, H. Greenhouse climate modelling and robust control. Comput. Electron. Agric. 2007, 61, 96-107. [CrossRef]

26. Sands, T. Development of Deterministic Artificial Intelligence for Unmanned Underwater Vehicles (UUV). J. Mar. Sci. Eng. 2020, 8, 578. [CrossRef]

27. Chen, C.; Khalil, H.K. Adaptive control of a class of nonlinear discrete-time systems using neural networks. IEEE Trans. Autom. Control 1995, 40, 791-801. [CrossRef]

28. Niu, B.; Wang, D.; Alotaibi, N.D.; Alsaadi, F.E. Adaptive neural state-feedback tracking control of stochastic nonlinear switched systems: An average dwell-time method. IEEE Trans. Neural Netw. Learn. Syst. 2019, 30, 1076-1087. [CrossRef]

29. Cheng, L.; Wang, Z.; Jiang, F.; Li, J. Adaptive neural network control of nonlinear systems with unknown dynamics. Adv. Space Res. 2021, 67, 1114-1123. [CrossRef]

30. Yao, D.; Dou, C.; Yue, D.; Zhao, N.; Zhang, T. Adaptive neural network consensus tracking control for uncertain multi-agent systems with predefined accuracy. Nonlinear Dyn. 2020, 101, 1-14. [CrossRef]

31. Wang, Y.; Chai, T.; Fu, J.; Sun, J.; Wang, H. Adaptive decoupling switching control of the forced-circulation evaporation system using neural networks. Control Systems Technology. IEEE Trans. Control Syst. Technol. 2013, 21, 964-974. [CrossRef]

32. Márquez-Vera, M.A.; Ramos-Fernández, J.C.; Cerecero-Natale, L.F.; Frédéric, L.; Jean-Franço, B. Temperature control in a MISO greenhouse by inverting its fuzzy model. Comput. Electron. Agric. 2016, 124, 168-174. [CrossRef]

33. Iddio, E.; Wang, L.; Thomas, Y.; McMorrow, G.; Denzer, A. Energy efficient operation and modeling for greenhouses: A literature review. Renew. Sustain. Energy Rev. 2020, 117, 109480. [CrossRef]

34. Lafont, F.; Balmat, J.F. Optimized fuzzy control of a greenhouse. Fuzzy Sets Syst. 2002, 128, 47-59. [CrossRef]

35. Noureddine, C.; Amine, A.; Anas, E.M.; Tarik, K.; Said, S.; Abdelmajid, J. Review on greenhouse microclimate and application: Design parameters, thermal modeling and simulation, climate controlling technologies. Sol. Energy 2019, 191, 109-137.

36. Henten, E.J.V. Sensitivity Analysis of an Optimal Control Problem in Greenhouse Climate Management. Biosyst. Eng. 2003, 85, 355-364. [CrossRef]

37. Xu, D.; Du, S.; Willigenburg, L.G.V. Optimal control of Chinese solar greenhouse cultivation. Biosyst. Eng. 2018, 171, 205-219. [CrossRef]

38. Boulard, T.; Wang, S. Greenhouse crop transpiration simulation from external climate conditions. Agric. For. Meteorol. 2000, 100, 25-34. [CrossRef]

39. Boulard, T.; Baille, A. A simple greenhouse climate control model incorporating effects of ventilation and evaporative cooling. Agric. For. Meteorol. 1993, 65, 145-157. [CrossRef]

40. Improna, I.; Hemming, S.; Bot, G.P.A. Simple greenhouse climate model as a design tool for greenhouses in tropical lowland. Biosyst. Eng. 2007, 98, 79-89. [CrossRef]

41. Atyah, N.; Afif, H. Modeling of greenhouse with PCM energy storage. Energy Convers. Manag. 2008, 49, 3338-3342.

42. Wang, Y.; Chai, T.; Fu, J.; Zhang, Y.; Fu, Y. Adaptive decoupling switching control based on generalised predictive control. IET Control Theory Appl. 2012, 6, 1828-1841. [CrossRef]

43. Zhang, J.; Sun, H.; Qi, Y.; Deng, S. Temperature control strategy of incubator based on RBF neural network PID. World Sci. Res. J. 2020, 6, 7-15.

44. Zhou, Y.; Wang, A.; Zhou, P.; Wang, H.; Chai, T. Dynamic performance enhancement for nonlinear stochastic systems using RBF driven nonlinear compensation with extended Kalman filter. Automatica 2020, 112, 108693. [CrossRef] 